Original Article

\title{
Characteristics of dynamic standing balance with and without an insole in patients with spastic diplegia cerebral palsy
}

\author{
YASUAKI KUSUMOto, RPT, PhD ${ }^{1)^{*}}$, Junko TsuchiYA, RPT, MSc ${ }^{1)}$, \\ Yoshiteru Watanabe, RPT, MSc ${ }^{1)}$, Masaru Umeda, MD, $\mathrm{PhD}^{1)}$, \\ Tadamitsu Matsuda, RPT, PhD ${ }^{2)}$, Kenji TAKaki, RPT, MSc ${ }^{3)}$, Osamu Nitta, RPT, PhD ${ }^{4}$ \\ 1) Department of Physical Therapy, Division of Health Science, Tokyo University of Technology: \\ 5-23-22 Nishikamata, Ohta-ku, Tokyo 144-8635, Japan \\ 2) Department of Physical Therapy, Faculty of Health Science, Juntendo University, Japan \\ 3) Department of Physical Therapy, Faculty of Health Sciences, Mejiro University, Japan \\ 4) Tokyo Metropolitan University, Department of Physical Therapy, Faculty of Health Sciences, \\ Tokyo Metropolitan University, Japan
}

\begin{abstract}
Purpose] This study examined characteristics of dynamic standing balance, with an without an insole, in patients with spastic diplegia cerebral palsy (CP). [Participants and Methods] This cross-sectional study used a crossover design. Eleven patients with spastic diplegia CP and gross motor levels between I and III with spastic diplegia CP (according to the Gross Motor Function Classification System expanded and revised version) were randomly allocated to either the barefoot or insole groups. The Index of postural stability (IPS) was evaluated while each patient was barefoot and while wearing insoles. The Pediatric Evaluation of Disability Inventory (PEDI) was used to measure functional self-care and mobility domains. [Results] While wearing the insoles, the center movement distance between right and left positions was significantly higher. While barefoot, IPS and area of postural sway correlated with the PEDI subscales for mobility and self-care. [Conclusion] Insoles promote standing balance and dynamic balance to move the center of pressure within the base of support. Such improvements may enhance activities of daily living in patients with spastic diplegia CP.

Key words: Spastic diplegia, Index of postural stability, Insole
\end{abstract}

(This article was submitted Jul. 31, 2019, and was accepted Oct. 17, 2019)

\section{INTRODUCTION}

Foot deformities are the most common problems among patients with cerebral palsy (CP) ${ }^{1}$. Ankle-foot orthosis (AFO) and insoles are used for the prevention and treatment of these problems ${ }^{2}$. The ankle-foot orthosis and insoles are usually used for patients with moderate/severe and mild foot deformity, respectively. In Japan, patients with CP often use AFO outside and insoles inside the shoes. Previous studies on patients with CP using insoles reported improvements of static standing and dynamic balance in timed up and go test and the gait parameters ${ }^{3,4)}$. The dynamic balance consists of the ability to move the center of pressure (COP) within the base of support (BOS) and to move COP from a BOS to another BOS. For patients with $\mathrm{CP}$, the insoles improve the dynamic balance to move COP from a BOS to another BOS such as in timed up and go test, and the gait parameters. It is suggested that the insoles will improve the dynamic balance of moving the COP within the BOS; however, this remains to be uncertain. The basic effects of insoles, as reported by a few studies, include improvement in impairment level. Because the dynamic balance to move COP within BOS is often facilitated in several treatments, it is a

*Corresponding author. Yasuaki Kusumoto (E-mail: kusumotoys@stf.teu.ac.jp)

(C)2020 The Society of Physical Therapy Science. Published by IPEC Inc.

(c) (i) $\odot$ This is an open-access article distributed under the terms of the Creative Commons Attribution Non-Commercial No Derivatives

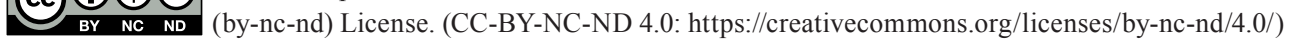


clinically important assessment point. If the use of insoles improves the dynamic balance among patients with CP, then they may be used to provide a more effective treatment. Therefore, this study aimed to investigate the characteristics of dynamic standing balance in the presence or absence of insole for patients with spastic diplegia CP.

\section{PARTICIPANTS AND METHODS}

Participants were recruited from three hospitals and medical centers in Tokyo and Kanagawa. The inclusion criteria were as follows: (1) diagnosis of spastic diplegia $\mathrm{CP}$; (2) ability to stand alone; (3) ankle deformities that were non-reducible to neutral; and (4) the ability to communicate and follow instructions. The exclusion criteria were orthopedic intervention or botulinum toxin injection to the lower extremities within the past 6 months. Eleven participants with spastic CP who met the inclusion and exclusion criteria were included in the study (Table 1). Participants and their parents provided informed consent for participation. The Ethical Review Board of the affiliated institution approved the study (authorization number: E19HS-001).

The trial had a cross-over design. Using the permuted block method, participants were randomly allocated to either the barefoot group or the insoles group. The insoles, which were manufactured for each participant, were used in the present study. The heels of each insole were raised by $0-5 \mathrm{~mm}$ in consideration of the range of motion and the muscle tonus of the participants' ankle joints. The insoles had a moderate medial longitudinal arch pad and a metatarsal pad which could be moved smoothly with the center of gravity in the sagittal plane. The first and second measurements were performed on the same day. Measurements for each group were performed after a 3-minute warm-up. The Index of postural stability (IPS) was evaluated while barefoot and while wearing shoes with insoles. The IPS measurement was carried out according to the previous study ${ }^{5,6)}$. From the measurements, IPS was calculated as " $\log [($ area of stability limit + area of postural sway)/area of postural sway]." IPS has no unit. The area of stability limit was defined as the "center movement distance between anterior and posterior positions $\times$ the distance between right and left positions". Area of postural sway was defined as "measurement value in 10 seconds as average of the 5 positions of sway area (center, anterior, posterior, right and left)."

The Pediatric Evaluation of Disability Inventory (PEDI) is a measure used for assessing a child's capabilities and performance in three domains: self-care, mobility and social functioning in daily life. Functional capability as measured by PEDI Functional Skills Scales (PEDI-FSS) describes a person's potential and includes 193 items rated as either capable (score 1) or incapable (score 0). Whereas actual performance as measured in PEDI Caregiver Assistance Scale (6-point ordinal scale, PEDI-CAS) describes the extent of help a parent gives in daily functioning. The PEDI has excellent reliability, validity and responsiveness in many studies ${ }^{7}$. In this study, only the scaled scores in the mobility and self-care domains of the PEDI-FSS and PEDI-CAS were used. The PEDI was evaluated by trained physical therapists through a structured interview with the parents.

The IPS, the center movement distance between anterior and posterior positions, the distance between right and left positions, and area of postural sway of both the groups were compared using paired t-test. The parameters of IPS and PEDI scores were assessed for each side using Pearson product-moment correlation. The analyses were performed using IBM SPSS Statistics for Windows (version 19.0); $\mathrm{p}<0.05$ was considered statistically significant.

\section{RESULTS}

The results of comparing each parameter between the barefoot and the insoles groups are presented in Table 2. While wearing the insoles, the center movement distance between right and left positions was significantly higher. Correlations of the parameters of IPS and PEDI scores are presented in Table 3. IPS while barefoot correlated with PEDI-CAS mobility and PEDI-FSS self-care. Area of postural sway while barefoot correlated with PEDI-CAS mobility. Moreover, the areas of postural sway while barefoot and while wearing insoles correlated with PEDI-FSS self-care.

\section{DISCUSSION}

In this study, the distance between right and left positions among patients with CP immediately improved with the use of insoles. The IPS and area of postural sway while barefoot correlated with PEDI-CAS mobility and PEDI-FSS self-care. These IPS parameters show the ability of dynamic balance to move COP within BOS. Spastic CP patients with diplegia have difficulty controlling selective voluntary movements ${ }^{8}$. Therefore, patients with $\mathrm{CP}$ often have insufficient motor control of 
Table 2. Comparison of parameters associated with not wearing and wearing the insoles

\begin{tabular}{lccc}
\hline & Barefoot & Insoles & p value \\
\hline IPS & $1.13 \pm 0.44$ & $1.12 \pm 0.41$ & 0.85 \\
$\begin{array}{l}\text { Center movement distance between } \\
\text { anterior and posterior positions }(\mathrm{cm})\end{array}$ & $4.9 \pm 2.6$ & $4.3 \pm 2.3$ & 0.15 \\
$\begin{array}{l}\text { Center movement distance between } \\
\text { right and left positions }(\mathrm{cm})\end{array}$ & $9.5 \pm 3.2$ & $11.4 \pm 4.0$ & $0.01^{*}$ \\
Area of postural sway $\left(\mathrm{cm}^{2}\right)$ & $5.3 \pm 5.3$ & $5.3 \pm 4.2$ & 0.97 \\
\hline
\end{tabular}

IPS: Index of postural stability. Mean \pm standard deviation. * ${ }^{*}<0.05$.

Table 3. Correlations of the parameters of IPS and PEDI score

\begin{tabular}{|c|c|c|c|c|}
\hline & $\begin{array}{l}\text { PEDI-FSS } \\
\text { mobility }\end{array}$ & $\begin{array}{l}\text { PEDI-CAS } \\
\text { mobility }\end{array}$ & $\begin{array}{l}\text { PEDI-FSS } \\
\text { self-care }\end{array}$ & $\begin{array}{l}\text { PEDI-CAS } \\
\text { self-care }\end{array}$ \\
\hline IPS (barefoot/insoles) & $0.19 / 0.13$ & $0.65 * / 0.34$ & $0.65 * / 0.55$ & $0.46 / 0.24$ \\
\hline $\begin{array}{l}\text { Center movement distance between anterior } \\
\text { and posterior positions (barefoot/insoles) }\end{array}$ & $0.15 / 0.14$ & $-0.03 /-0.13$ & $0.39 / 0.21$ & $0.16 / 0.03$ \\
\hline $\begin{array}{l}\text { Center movement distance between right } \\
\text { and left positions (barefoot/insoles) }\end{array}$ & $0.17 / 0.48$ & $0.25 / 0.10$ & $0.39 / 0.37$ & $0.19 / 0.19$ \\
\hline $\begin{array}{l}\text { Area of postural sway } \\
\text { (barefoot/insoles) }\end{array}$ & $-0.44 /-0.09$ & $-0.92 * /-0.56$ & $-0.67 * /-0.66^{*}$ & $-0.53 /-0.39$ \\
\hline
\end{tabular}

the lower limbs that allow stabilization and balance while standing. Because the lateral movement distance of center of pressure was higher in this study, the dynamic balance to move COP within BOS in patients with diplegia CP may be facilitated by wearing insoles. While it was suggested that wearing the insoles could improve the dynamic balance to move the COP within the BOS, such as in the case of IPS, the results negated this. In the case of IPS, the distance of the center of movement between the anterior and posterior positions and the area of postural sway were not significant. For spastic CP patients with ankle deformities that were non-reducible to neutral, the insoles in said case were insufficient to affect the center movement distance in the sagittal plane and the ability of the dynamic balance to move COP within BOS.

Several studies on patients with $\mathrm{CP}$ have reported correlations between dynamic balance and activities of daily living ${ }^{9-11)}$. However, most of these showed the dynamic balance to move COP from a BOS to another BOS. Because IPS and area of postural sway while barefoot correlated with performance of mobility and capabilities of self-care, it is clear that the dynamic balance to move COP within BOS correlates with activities of daily living. The presence or absence of correlations between the parameters of IPS and PEDI scores may reveal important causes which communicate the need to assess the dynamic balance while barefoot.

This study has some limitations. The age range of participants in the study was wide. Typical daily movements are some of the main causes of motor function changes and joint contracture among patients with $\mathrm{CP}^{12}$ ). Therefore, further studies with a selected age range of participants that aim to determine the longitudinal motor function changes are needed to overcome these limitations.

Because the dynamic balance of the IPS results such as lateral movement of the center of pressure were better when wearing insoles and IPS parameters while barefoot correlated with performance of mobility and capabilities of self-care, it can be concluded that the insoles are effective for promoting the standing balance and the dynamic balance to move COP within BOS. It also correlates with activities of daily living for patients with spastic diplegia CP.

\section{Conflict of interest}

The authors declare no conflict of interest.

\section{REFERENCES}

1) Karamitopoulos MS, Nirenstein L: Neuromuscular foot: spastic cerebral palsy. Foot Ankle Clin, 2015, 20: 657-668. [Medline] [CrossRef]

2) Kedem P, Scher DM: Foot deformities in children with cerebral palsy. Curr Opin Pediatr, 2015, 27: 67-74. [Medline] [CrossRef]

3) Pasin Neto H, Grecco LA, Ferreira LA, et al.: Postural insoles on gait in children with cerebral palsy: Randomized controlled double-blind clinical trial. J Bodyw Mov Ther, 2017, 21: 890-895. [Medline] [CrossRef]

4) Neto HP, Grecco LA, Duarte NA, et al.: Immediate effect of postural insoles on gait performance of children with cerebral palsy: preliminary randomized controlled double-blind clinical trial. J Phys Ther Sci, 2014, 26: 1003-1007. [Medline] [CrossRef] 
5) Mochizuki H, Mineshima T: Reliability and validity of the Index of Postural Stability using forceplates. Rigaku Ryoho Gaku, 2000, 27: 199-203 (in Japanese).

6) Suzuki Y, Yatoh S, Suzuki H, et al.: Age-dependent changes in dynamic standing-balance ability evaluated quantitatively using a stabilometer. J Phys Ther Sci, 2018, 30: 86-91. [Medline] [CrossRef]

7) James S, Ziviani J, Boyd R: A systematic review of activities of daily living measures for children and adolescents with cerebral palsy. Dev Med Child Neurol, 2014, 56: 233-244. [Medline] [CrossRef]

8) Kusumoto Y, Hanao M, Takaki K, et al.: Reliability and validity of the Japanese version of the selective control assessment of the lower extremity tool among patients with spastic cerebral palsy. J Phys Ther Sci, 2016, 28: 3316-3319. [Medline] [CrossRef]

9) Yi SH, Hwang JH, Kim SJ, et al.: Validity of pediatric balance scales in children with spastic cerebral palsy. Neuropediatrics, 2012, 43: 307-313. [Medline] [CrossRef]

10) Gan SM, Tung LC, Tang YH, et al.: Psychometric properties of functional balance assessment in children with cerebral palsy. Neurorehabil Neural Repair, 2008, 22: 745-753. [Medline] [CrossRef]

11) Pavão SL, dos Santos AN, Woollacott MH, et al.: Assessment of postural control in children with cerebral palsy: a review. Res Dev Disabil, 2013, 34: 13671375. [Medline] [CrossRef]

12) Terjesen T: The natural history of hip development in cerebral palsy. Dev Med Child Neurol, 2012, 54: 951-957. [Medline] [CrossRef] 